\title{
International publishing as a networked activity: Collegial support for Chinese scientists
}

\section{EAL academics, Chinese scientists and scholarly publishing}

Rapid globalization and the expansion of appraisal mechanisms have put new pressures on academics around the world to publish in prestigious English language journals. The rhetorical challenges these demands impose on all academics, regardless of first language, are considerable, as the ability to present themselves authoritatively in the dual space of content (subject knowledge) and rhetoric (discursive competence) is largely acquired with experience (Hyland 2015, 2016; Swales 2004). However, the burden falls particularly heavily on EAL (English as an Additional Language) academics as discursive barriers are often exacerbated by limited English proficiency and reduced familiarity with Anglophone academic conventions.

While minor language problems seldom lead to rejection (Belcher 2007; Rozycki and Johnston 2013), limited proficiency in English can seriously compromise the presentation of research, producing manuscripts which are hybrids of sophisticated disciplinary concepts and simplistic expressions (Burrough-Boenisch and Matarese 2013). With many top journals rejecting up to $90 \%$ of the submissions they receive (Hyland 2015, 2016), non-standard language or inappropriate presentation can lead to rejection and demoralization.

Many Chinese scientists have been enormously successful in publishing in international journals, with double-digit annual growth in recent years and now accounting for $18.6 \%$ of the global total of papers appearing in Science Citation Index (SCI) journals (ISTIC 2018). The success of Chinese authors can partly be attributed to their success in forming international collaborations, with more than half of China's published research on the prestigious Nature Index now including international co-authors (Anderson 2017). Much of this increase, however, is the result of the massive rise in the number of academics entering the game. China, for example, now boasts the largest number of $\mathrm{PhD}$ students in the world (Cryanoski et al. 2011), all of whom must publish to graduate and further their careers (Luo 2017; Mu and Zhang 2018). Established academics must also continue to publish to keep their jobs and perhaps to hugely increase their salaries, with financial incentives to publish internationally often considerable and rising to US\$64,000 for authors appearing in Nature or Science (Prest 2017).

The consequent surge in submissions to journals from China, however, has not enjoyed a corresponding increase in acceptances. The period from 2005 to 2010, for instance, saw a 
substantial growth of $484 \%$ in submissions from China to ScholarOne journals while the acceptance rate increased only from $26.2 \%$ to $26.8 \%$. This contrasts with acceptance rates of the traditional publishing nations of the US, UK and Japan of around 40-50\% (Hyland 2015). Citation rates for Chinese authored papers also remain below the world average (ISTIC 2018). These figures perhaps reflect the limited training Chinese scientists receive in writing for publication and the struggles they face in English academic writing (Daly 2016). They typically lack international contacts to create the kinds of broker relationships discussed by Lillis and Curry (2010) for European scholars. As a result, Chinese scientists often seek to publish in low impact SCI journals (Fu et al. 2013) or in obscure non-SCI journals (Luo 2017), perhaps giving up publishing internationally altogether (Luo and Hyland 2019; Mu and Zhang 2018). Several studies therefore report Chinese scientists calling for more writing support (Luo 2017; Li and Flowerdew 2007).

\section{International publishing as a networked activity}

Research into writing for academic publication by non-native English (EAL) speakers tends to emphasize the "unequal status and power" existing between participants as a result of differential access to knowledge and other intellectual and material resources (Lillis and Curry 2010). This conflictual, adversarial model presents a system loaded against EAL scholars who largely have to depend on the support of Anglophone centre 'text brokers' due to a shortage of local provision. In contrast to this 'Academic Literacies' approach, we seek to explore the collaborative relationships between academics, arguing that knowledge production is generally a collective and collegial endeavor.

Collaboration is promoted by many institutions and funding bodies around the world as a means of sharing technological apparatus, expertise and access to data. Technology has certainly increased global information flows and resource networks but much research remains local and the kinds of support offered by colleagues goes unrecorded. The academy recognises only some roles in the creation of research papers. Although responsibility, accountability and the recognition of a division of intellectual and writing labour have recently been acknowledged in some scientific journals (e.g. http://www.icmje.org), this fails to recognise broader support mechanisms which authors may rely on. Hence, the collective dimension of knowledge production often remains below the surface.

EAL academics, including Chinese scientists, often solicit support from others to work on their English texts for international publication. Seeking advice from friends or colleagues 
down the corridor or over the internet underlines how writing for publication is more of a networked activity than an individual endeavor (Canagarajah 2018; Lillis and Curry 2006). These others include coauthors and non-authorial text mediators ${ }^{1}$ of various kinds (Luo 2017; Burrough-Boenisch, 2003; Li and Flowerdew 2007). The diversity of people providing assistance in these situations suggests that EAL researchers do not need to possess a full range of research and literacy abilities themselves to successfully publish in English. Lillis and Curry (2006) and Luo and Hyland (2019), for example, show how non-Anglophone scholars with very limited English proficiency manage to publish internationally by collaborating with colleagues and/or using professional translation services. Thus, Canagarajah (2018: 16) argues:

"competence" should not be attributed to the individual or to his/her mind, but to the network of resources and agents that generate the text.

These networks have traditionally been seen as comprising colleagues personally known to authors and who shared or complemented their disciplinary knowledge. This group can offer valuable assistance as coauthors or text mediators (Burrough-Boenisch 2003; Gholami and Zeinolabedini 2017; Li and Flowerdew 2007). Co-authors not only complement the discipline knowledge of the main author(s), but also have a stake in the manuscript. Text mediators offer assistance without appearing in the byline. Non-colleague helpers, such as commercial text mediators and English teachers, can also provide valuable help (Luo and Hyland 2016, 2017; Flowerdew and Wang 2016), but are usually excluded from discussions of academic networks.

In this paper, we take the idea of publishing networks to include those frequently omitted from the picture, showing how colleagues, defined as active researchers from the author's broad disciplinary circle, assist EAL scholars in constructing English texts for publication in international journals, either as coauthors or text mediators.

\section{Collegial support for EAL academics}

Colleagues are considered to be pivotal members of an author's networked resources as they can offer advice which is trusted, free, and which goes beyond surface-level grammar fixes (Li and Flowerdew 2007; Burrough-Boenisch 2003). Such colleagues can therefore both help create effective arguments in English and step in to complement an author's literacy abilities at the revision stage. 
Colleagues may be, and often are, collaborators who are listed as co-authors on a paper. Academic coauthoring has grown rapidly in recent years, particularly in the physical sciences (Hyland 2015) where the rise of "big science" and interdisciplinary research means that scientists have become more collaborative than ever before. Even in the social sciences multiauthored paper have increased, with over $90 \%$ of economics papers being single authored in the 1960s to just $25 \%$ today (Kuld and O'Hagan 2017). Such co-authorship relationships often involve complex divisions of labour among members of research groups with clear responsibilities for individuals (e.g. Latour and Woolgar 2013). The more proficient or experienced members are likely to take on writing or editing roles for the group (Lillis and Curry 2010). In cases where a research student drafts a paper, the most important collegial support is often the supervisor(s) who may substantially shape the paper (e.g. Canagrajah 2018; Li 2012).

In China, coauthoring with their students is a key responsibility for supervisors, as publishing SCI papers is a precondition for PhD graduation (Luo 2017; Li 2012). Supervisors are held responsible for the research integrity of their students and are the default corresponding authors of their students' first-authored papers. Supervisors also benefit from this activity in the form of cash rewards, career advancement and further funding if their students succeed in publishing in prestigious SCI journals (Luo 2017). These official arrangements tie supervisors and students into a relationship of mutual dependence in international publishing. Sometimes, former supervisors may continue to support the publication efforts of their students beyond graduation. For many novice scientists, publishing in prestigious international journals would have been impossible if not for their supervisors' support ( $\mathrm{Li} 2012)$.

Another network resource among colleagues for Chinese academics is overseas researchers (Li 2014a). It is not uncommon for EAL scholars to invite international colleagues to coauthor papers to overcome discursive barriers, offering a strategy which potentially yields high returns without financial cost (Jiang et al. 2017; Li 2014a). Overseas researchers may also help shape scholars' texts without being credited with authorship.

Finally, more discursively competent local colleagues may be recruited from within a network to work on manuscripts with or without sharing authorship. While these colleagues are certainly a valuable network resource, there have been few studies of their importance or role. However, Lillis and Curry (2010), investigating non-Anglophone European academics in education and psychology, conclude that colleagues are the most valuable publishing resource for EAL scholars, a finding echoed by Li (2014b) studying a group of surgeons at a Chinese 
hospital. Research on Iranian medical scholars, on the other hand, found that colleagues lacked the confidence and literacy skills to rectify their fellow researchers' papers (Gholami and Zeinolabedini 2017; Zeinolabedini and Gholami 2016).

To understand the role of collegial resources more generally, we investigated the international publishing processes of 31 Chinese scientists at various career stages in different disciplines. For our purposes, a scientist is a researcher who seeks to publish internationally, including doctoral students, postdoc fellows, faculty members and medical doctors.

We intend to answer the following questions:

1) To what extent do Chinese scientists make use of colleagues in writing for international publication?

2) Who contributes to this process and in what ways?

\section{Methodology}

\section{Participants}

To draw a broad picture of the collegial support which Chinese scientists receive for international publication, we adopted maximum variation sampling, a purposeful sampling approach widely used in qualitative studies, to show as much variation as possible across the data (Coyne 1997). To begin with, the first author posted a recruiting message online in Chinese and also sent it to her contacts in the academy in China, inviting scientific authors at different career stages from different disciplines to participate in the study. Forty-five scientists responded, and we selected 31 from 11 institutions, ranging from highly-resourced top-tier national universities to under-resourced low-ranking regional ones, based on the following two criteria:

- Participants should have international publishing experience;

- They should represent a range of age groups, career stages, educational backgrounds, institutions and experiences in international publishing.

Among the participants, there were a supervisor-supervisee pair and an in-group authormediator dyad. They were fully aware of a colleague's participation in the project. Key information of the participants is shown in Table 1. 
Table 1: Participants' career stage, discipline and main authoring experience

\begin{tabular}{|c|c|c|c|c|c|c|}
\hline Discipline & $\begin{array}{l}\text { Doctoral } \\
\text { student }\end{array}$ & Postdoc & Lecturer & $\begin{array}{l}\text { Associate } \\
\text { professor }\end{array}$ & Professor & $\begin{array}{l}\text { Medical } \\
\text { doctor }\end{array}$ \\
\hline Medicine & $\begin{array}{l}\text { DS1(1) } \\
\text { DS2 (1) }\end{array}$ & PD (3) & & AP1 (7) & Prof1 (>25) & $\begin{array}{l}\text { MD1 (3) } \\
\text { MD2 (5) } \\
\text { MD3 (12) } \\
\text { MD4 (4) }\end{array}$ \\
\hline $\begin{array}{l}\text { Electrical } \\
\text { engineering }\end{array}$ & DS3 (3) & & & $\begin{array}{l}\text { AP2 }(>10) \\
\text { AP3 }(\approx 20)\end{array}$ & $\begin{array}{l}\text { Prof2 }(>25) \\
\text { Prof3 }(>30)\end{array}$ & \\
\hline Biology & DS4 (2) & & & $\begin{array}{l}\text { AP4 }(>20) \\
\text { AP5 }(>60) \\
\text { AP6 }(>15)\end{array}$ & & \\
\hline $\begin{array}{l}\text { Mechanical } \\
\text { engineering }\end{array}$ & & & L1 $(>10)$ & AP7 (1) & $\begin{array}{l}\text { Prof4 (3) } \\
\text { Prof5 (2) }\end{array}$ & \\
\hline $\begin{array}{l}\text { Material } \\
\text { science }\end{array}$ & & & L2 (4) & AP8 $(\approx 10)$ & Prof6 (>20) & \\
\hline $\begin{array}{l}\text { Computer } \\
\text { science }\end{array}$ & & & & $\begin{array}{l}\text { AP9 (>15) } \\
\text { AP10 (1) }\end{array}$ & & \\
\hline Mathematics & & & & & Prof7 (16) & \\
\hline Chemistry & & & L3 (4) & & & \\
\hline Geology & DS5 (1) & & & & & \\
\hline Mining & & & & & Prof8 $(\approx 10)$ & \\
\hline $\begin{array}{l}\text { Total subjects } \\
\& \text { lead papers }\end{array}$ & $5(8)$ & $1(3)$ & $3(>18)$ & $10(>159)$ & $8(131)$ & $4(24)$ \\
\hline
\end{tabular}

The number of English papers each participant lead-authored is shown in brackets. Prof3-DS3 was the supervisor-supervisee pair and DS2-MD1 the author-mediator dyad.

The 31 participants were from 10 disciplines and ranged across 6 career/experience categories. All were required to publish in international journals, the doctoral students to meet graduation requirements and the others for professional career advancement. Among the 18 professorial participants, only 8 were supervising $\mathrm{PhD}$ students when they were interviewed. Due to the limited sample size in each discipline and career stage, we are unable to make meaningful comparisons across these dimensions.

\section{Data collection and analysis}

All participants were interviewed in Chinese for around an hour using a semi-structured format. Most interviews were conducted face-to-face and recorded while three scientists were geographically inaccessible and thus interviewed via QQ, a popular synchronous instant messaging service, through text chat. Since all the scientists were asked similar questions and were similarly forthcoming in their responses, we do not believe the mode of interview, faceto-face or text-chat, influenced our results. All interviewees signed informed consent forms before the interviews. We also asked for, and were given, manuscripts at different stages of 
development being prepared for publication together with correspondence (generally emails) between the scientists, coauthors, mediators and with journal editors.

The recorded interviews were transcribed and the QQ ones reformatted for clarity. These texts were checked by the interviewees for accuracy before they were entered into MAXQDA (a qualitative data analysis program) together with the communication records for open and axial coding (Saldaña 2013). For open coding, data were read carefully and assigned codes according to our interpretations of the function of the comment. In addition to generating codes about collegial actions and attitudes, this process also identified four types of colleagues, based on their expected roles:

- Supervisors of PhD students and postdoc fellows

- International coauthors

- Colleagues who serve as non-authorial text mediators

- Local coauthors (excluding supervisors)

The codes were then grouped into axial codes or categories which sought to organize them according to a higher level or more general category of action (see Table 2). The codes and categories were gradually refined over several passes through the data over a number of months by the first author as the second author does not speak Chinese.

Table 2: An example of qualitative data coding

\begin{tabular}{|l|r|r|}
\hline \multicolumn{1}{|c|}{ Qualitative data excerpts } & codes from open coding & $\begin{array}{c}\text { category from axial } \\
\text { coding }\end{array}$ \\
\hline $\begin{array}{l}\text { A1: My supervisor gave it a friend...But we } \\
\text { never received any response. }\end{array}$ & silent rejection & \\
\hline $\begin{array}{l}\text { DS2: When I asked my former classmate to } \\
\text { check my paper...she sent it back to me } \\
\text { quickly...there were only a few changes. }\end{array}$ & perfunctory editing & Lack of commitment \\
to text mediation \\
$\begin{array}{l}\text { DS5: My former classmate thought it [the } \\
\text { paper] was poorly translated. So he translated } \\
\text { one paragraph and told me to demand the [paid] } \\
\text { translator to retranslate, following his sample. }\end{array}$ & minimal translation & \\
\hline $\begin{array}{l}\text { PROF2: As a colleague, I do not see why I } \\
\text { should waste my time in such favors [of editing } \\
\text { papers for colleagues]. }\end{array}$ & antipathy & \\
\hline
\end{tabular}

Our main focus was on these interview responses but we also consulted the textual data where necessary. The textual data also underwent two analytical cycles, one based on the revision actions undertaken by colleagues and the other on the functional effect these revisions 
had on the texts. We used Willey and Tanimoto's (2012) taxonomy to analyze revision actions, but modified this to differentiate changes of different sizes, which we coded as minor, meso and major. A minor revision is one affecting fewer than five words, a meso one between six and ten, and a major one of more than ten words. While the divisions are arbitrary, they captured how the changes clustered and allowed us to understand both the function and the extent of the revision made. Since revisions obviously have effects on the meaning of texts, we also examined changes in generic features and in the thematic progression of sentences across drafts. Together our analyses of the texts allowed us to trace the impact of colleagues' revisions. The texts were coded by both authors with an inter-coder agreement rate of $90.7 \%$.

\section{The contribution of colleagues}

In this section, we explore authors' support networks in more detail by examining agents and activities: who contributed to their efforts to publish in international journals and in what ways. All the scientists in our study produced English manuscripts with the aid of others, supporting the idea that international publishing is very much a networked activity. The majority $(30,88 \%)$, however, still believed that they needed more assistance. In general, 18 out of 20 scientists in senior positions (16 professorial staff members and two doctors) appeared more confident about their ability to produce effective manuscripts acceptable to international journals and saw their greatest need for support in sentence-level language issues. In contrast, the junior scientists expressed a need for support in both language and rhetoric. Those providing writing support are shown in Table 3.

Table 3: Types of collegial support

\begin{tabular}{|c|c|c|c|c|}
\hline \multicolumn{2}{|c|}{ colleague } & $\begin{array}{c}\text { non-colleague } \\
\text { text mediator }\end{array}$ \\
\hline \multicolumn{3}{|c|}{ coauthor } & non-author text mediator & $19(61 \%)$ \\
\cline { 1 - 2 } supervisor & $\begin{array}{c}\text { international } \\
\text { collaborator }\end{array}$ & $\begin{array}{c}\text { other local } \\
\text { coauthors }\end{array}$ & & \\
\hline $12(39 \%)$ & $8(26 \%)$ & $2(6 \%)$ & $(22 \%)$ & \\
\hline
\end{tabular}

Most scientists in the study $(23,74 \%)$ had asked colleagues for writing support and 19 $(61 \%)$ also turned to non-colleague text mediators. Only three participants reported that they never turned to others for help themselves. Clearly, for the majority, writing for international publication is very much a networked activity. 
The first thing to say is that the people to whom the scientists turned for help in developing their English manuscripts were not all senior academics but varied across career stages. AP3, for example, relied on her husband, a university English teacher, as her text mediator but then coauthored with her supervisor as a postdoc researcher in Hong Kong. After becoming an associate professor, she coauthored low stakes papers with her graduate students while collaborating with her postdoc supervisor to publish in more prestigious ISI journals.

Supervisors, in fact, were the most important collegial support for our writers with 12 (39\%) reporting that they had obtained language assistance from their supervisors or exsupervisors. Meanwhile, eight researchers also received support from international collaborators (26\%), seven from colleagues who served as non-authorial text mediators (22\%) and two from other local coauthors $(6 \%)$. Below, we discuss the extent that our participants relied on different types of colleagues for English text production, taking in turn supervisors, international co-authors, mediators and local co-authors.

\section{Supervisors}

The most important resource in authors' collegial networks appeared to be supervisors with 12 relying on them to varying degrees. The eight participants who supervised graduate students reported that they spent considerable time and effort helping their students to publish in international journals. Interviews with the five doctoral students contradicted this, however. DS2 and DS5 denied that their supervisors were involved in their English text production at all while analysis of DS1's English manuscript showed her supervisor changed nothing after reading it. Another two students reported that their supervisors did not go beyond a light editing of their manuscripts. Only DS4 expressed a clear appreciation of her supervisor's intervention. While Prof3 claimed that he was involved in shaping the English manuscripts of his doctoral students, his student, DS3, recounted:

He mainly discussed the conclusion with me. As for how to write, he didn't meet with me and seldom helped.

Examining the manuscripts supported the students' remarks. For instance, Prof3 only made minimal changes to a conference paper drafted by DS3. In addition to inserting two comments in Chinese on the figures, he only deleted an 11-word chunk of text and made another eight single-word deletions. None of these changes made any significant impact on the paper.

Overall 19, scientists recounted their experience of publishing internationally during their $\mathrm{PhD}$ programs, eight of whom were now supervisors themselves. Nine of these $19(47 \%)$ 
denied that their $\mathrm{PhD}$ supervisors had provided them with any discursive support at all and the remainder stated that they had received some limited help, although this was not always very effective:

The papers my supervisor edited were still criticized for language. Every time, reviewers would suggest editing by a native English speaker. (AP1)

Among the supervisors reported to be highly helpful, five were international scholars and only seven participants said that their Chinese supervisors provided writing support.

The participants who stated that their PhD supervisors failed to assist them with English manuscripts gave two reasons to account for this. The first was that some supervisors had limited proficiency in English and lacked experience in international publishing themselves. For example, when AP3 drafted her first paper in English as a doctoral student, she did not show it to her PhD supervisor because the only foreign language he had learnt was Russian. Since most of these participants' $\mathrm{PhD}$ supervisors were educated in an era when international publication was rare in China, most lacked the confidence and skills to shape supervisees' English manuscripts. Even those with some experience of international publishing, like DS1's $\mathrm{PhD}$ supervisor who had worked as postdoc fellow in the US, found the task of commenting on their students' English papers challenging. As a result, some advised their students to pay for professional text mediation services and reimbursed the cost themselves (e.g. DS1's supervisor), while others simply left their students to sink or swim (e.g. DS5's supervisor).

Six of the eight $\mathrm{PhD}$ supervisors in this study (75\%) acknowledged that they lacked the ability to advise their students on writing in English. Several said they either drew on international collaborators or local English teachers (e.g. AP4, Prof2) for help. Half the supervisors, including two who could occasionally obtain writing support from collaborators, were still struggling to find reliable support when interviewed:

It's not I didn't want help. I asked many people but were always turned down. They often said "this stuff is too difficult for me". It's not easy for us. (Prof4)

I really want to find somebody to help but don't know who can. You mentioned online services. But they are costly!

This finding resonates with previous studies that Chinese scientists, including supervisors on the highest rungs of the academic ladder, have struggled with writing for international publication (Liu et al. 2015). While there are those that are competent and willing, many are unable to support supervisees' international publishing ambitions ( $\mathrm{Li}$ and Flowerdew 2007). 
They are, however, sometimes able to support them in other ways. Lei and $\mathrm{Hu}$ (2015), for instance, have identified four roles for doctoral supervisors in China: i) the topic hunter who searches research topics for students, ii) the research manager who helps students plan research and develop publishing plans, iii) the manuscript shaper who directly intervenes in studentdrafted manuscripts and iv) the publishing master who strategically guides students through the publishing process. In general, Chinese supervisors played the roles of topic hunter and research manager more often and relatively successfully, but often failed to live up to their supervisees' expectations as manuscript editors and publishing masters. Our study concurs with this finding as supervisors tended to offer advice on ideas rather than publishing.

This situation is by no means confined to China. Martinez and Graf (2016), for example, report that Brazilian $\mathrm{PhD}$ students, when drafting and revising English manuscripts, felt "abandoned" by supervisors who acknowledged their own deficiency in academic writing. Similarly, Duszak and Lewkowicz (2008) found that senior scholars in Poland are often less proficient in English than junior ones. For home-educated EAL scholars, it may be the norm that they find international publication beyond their control, either alone or when helping supervisees.

A second reason participants gave to explain why their $\mathrm{PhD}$ supervisors failed to assist them with English was a simple lack of commitment. As established scholars, many $\mathrm{PhD}$ supervisors hold key administrative posts in their institutions and lack the time to work on their students' papers. DS2 observed:

Supervisors won't get involved in writing papers, unless they are very young...My supervisor only told us how many SCI papers each of us has to publish. He cares only about the result, not the process.

Supervisor indifference to graduate students' academic publishing is not new. Some may be too preoccupied with other responsibilities to provide substantial support (Simpson 2013) or have little interest in helping supervisees to publish at all (Kwan 2010).

Even if a supervisor assists his or her students to publish, this support usually terminates when the student graduates, as we might expect. Supervisors have other students and research projects and often do not have the time to continue to mentor and support ex-students. Perhaps more surprising is that three authors (AP1, AP3, AP5) continued to work with former supervisors after the formal relationship ended, although the support they received diminished considerably. While AP3 and AP5 continued to collaborate with their postdoc supervisors in Hong Kong and the US, the collaboration was limited to only a few papers bidding for the most 
prestigious journals. AP1 had received considerable support from his supervisor who not only worked on manuscripts himself, but also solicited discursive support from a Canadian collaborator for him when he was a doctoral student. However, the collaborator's assistance ended with his graduation. Networks changes and may not always offer the support that authors require.

\section{International coauthors}

Although supervisors comprised the largest group of colleagues in these networks, all the participants believed, sometimes without evidence, that international peers, and particularly senior Anglophone researchers, would potentially offer the best support. Two writers involved in such collaborations observed:

We [Chinese authors] only report the facts but he [Hong Kong collaborator] always added a few sentences to the end of my introduction. Only a few sentences, but the whole article is immediately transformed! The argument becomes much stronger. (AP3)

The lead researcher in that group was very good at writing. His editing alone upgraded the impact factor of our target journal by at least two! Incredible, really incredible!

(Prof1)

While such comments may seem overly enthusiastic, our textual analyses confirmed these improvements. A comparison of the pre- and post-intervention versions of a manuscript drafted by Prof1's research group, for example, shows that his US collaborators almost completely rewrote the text. They removed $38 \%$ of the words in the introduction and $33 \%$ of those in the discussion, reformulated the move structure, and revised the theme progression throughout. Fig. 1 is an illustration of this. 
Figure 1: A screenshot of the paper rewritten by Profl' US collaborator

\begin{abstract}
It is knownhas been reported that therease the cardiac glycoside ouabain can increase the late sodium current (Ival) ean inerease reverse), as well as the diastolic intracellular calcium concentration and contractile shortening. Whether an increase of INa.L participates in a pathway that can mediate the positive inotropic response to ouabain is unknown. We therefore determined the effects of ouabain on INat, reverse-mode $\mathrm{Na}^{+}-\mathrm{Ca}^{2+}$ exchange current (reverse INcx) following by $\mathrm{I}$ ), intracellular $\mathrm{Ca}^{2+}$ levels ([Ca $\left.{ }^{2+}\right] \mathrm{i}$ aceumulation. To

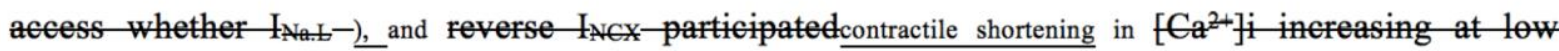
concentrations of oubain, $\mathrm{H}_{\mathrm{N}-\mathrm{L}}$ and reverse $\mathrm{H}_{\mathrm{N}}$, calcium transient and ventricular myocyte contractility were recorded simultaneously respectively in-rabbit isolated fabbit-ventricular myocytes. Our results-showed that etabain of - Ouabain $(0.1-8.0 \mu \mathrm{M})$ markedly increased INat and reverse INcx in a concentration--dependent manner-which could be-suppressed by $2.0 \mu \mathrm{M}$, with significant effects at concentrations as low as 0.5 and $1 \mu \mathrm{M}$. These effects of ouabain were suppressed by the Ivat inhibitors tetrodotoxin (TTX), and ranolazine the protein kinase C (PKC) inhibitor bisindolylmaleimide (BIM), and the $\mathrm{Ca}^{2+}$-calmodulin-dependent protein kinase II (CaMKII) inhibitor KN-93. The enhancedEnhancement of by $0.5 \mu \mathrm{M}$ ouabain of
\end{abstract}

Even in cases where international collaborators simply edited the language, they were considered highly helpful:

To develop really good manuscripts...we must obtain support from peers in the English-speaking countries...So we always invited such a person to edit before submission...but they concentrate on the language without changing our argument because we are the lead authors.

(AP4)

Two of our subjects received occasional discursive help from international collaborators who did not ask for co-authorship, thus blurring the boundary between co-author and nonauthorial mediator. One was AP5 who reported that his postdoc-supervisor-turned collaborator in the US would occasionally polish manuscripts for him if asked. Another was AP1 whose first English manuscript was edited by a Canada-based Chinese researcher, a long-term collaborator of his supervisor, without sharing authorship.

Despite this, only eight authors in our sample (26\%), including the two who continued to collaborate with their postdoc supervisors, had coauthored papers with international academics. Moreover, some scientists said they could only count on their international coauthors for discursive help occasionally, and generally less than they would like. For example, while Prof1 had collaborated with a US-based lab working on similar topics since 2006, most of his papers were edited by a local English teacher as he had become frustrated with his overseas colleagues' declining to revise papers based on studies they had not been 
involved in. He saw this as a lack of commitment to editing manuscripts. Similarly, L3, whose research group had strong collaborative ties to a British research team, was often frustrated by the British coauthors who sometimes took six months to return an ongoing paper:

While we are often very anxious, it's embarrassing to remind them again and again.

These frustrations ended in L3's group initiating a text mediation tie with a local English language professional and only turning to the British collaborators when aiming at top journals.

Some scientists were unable to obtain discursive support from overseas collaborators for other reasons. For instance, Prof 1 preferred not to involve his US collaborators if he had used a theoretical stance they would not endorse. In fact, AP4 was the only participant who claimed that his research group could rely solely on Anglophone collaborators for discursive issues. However, the lead researcher in his group approached different people, including the first author of this paper, for text mediation.

Our study shows that international senior scholars, particularly Anglophone-based ones, can be extremely valuable for EAL scholars' success. However, despite a steady growth in coauthoring between Chinese and international colleagues in recent decades (Jiang et al. 2017; Li 2014a), only14.4\% of the SCI papers first-authored by Chinese researchers in 2017 included Anglophone-based coauthors (ISTIC 2018). Few Chinese have the overseas experience or contacts to make such partnerships a solution to their discursive problems. Indeed, possibilities for collaboration may actually recede further due to concerns, particularly in the US, about alleged Chinese economic and political espionage and technology theft.

Certainly, our subjects lacked the contacts to build such a relationship. Only those who had studied abroad (e.g. AP5) or who had established connections with Anglophone research groups (e.g. Prof1) were able to do so. Even when a trusted relationship was established, it could be fragile and was not usually drawn on if there was no collaboration in the study. The fact that online fee-paying text mediation services have thrived in recent years (e.g. Kaplan 2010; Kim 2019) suggests that despite the desire among Chinese scientists to build collaborative ties with international senior scholars, such relationships are difficult to initiate and nurture. International collaboration is clearly not the panacea scientists hope for.

\section{Colleagues as mediators}

In all, ten authors (32\%) requested help from 17 local colleagues for text mediation assistance without offering co-authorship, with only seven such requests (41\%) being successful in terms of uptake. This suggests a clear reluctance by colleagues to give pro bono 
discursive support, reflecting the time and effort involved for little return to the mediator. Three of the four scholars who had returned from work or study overseas were approached multiple times but showed strong antipathy to it and did not hesitate to refuse:

Yes, I was asked a few times. However, I won't get involved. Since I don't know much about their topics, it would take me too much time, very likely without good results.

(AP3)

I occasionally helped a little at the beginning. But I decline now... I don't see why I should spend my free time in giving favors.

(Prof2)

I reject most requests now. I worked really hard on colleagues' papers in the early days. But there were so many of them. How could I possibly spend all my time on their papers... Now if I agree to have a look I only comment very generally... (Prof6)

The reluctance of colleagues to provide editing, translating, rewriting or advice on manuscripts is also shown in the textual data. Track-changes histories show that most mediators made only a small number of minor edits and comments, contributing little to the manuscripts. A good example is DS2's manuscript. DS2 was a PhD candidate in medicine who, despite asking, had had little success in soliciting free mediation services from colleagues. He first sent his manuscript to Lily for editing, a proficient English speaker he had known as an undergraduate. He then sent it to Dong, a PhD colleague who had volunteered to edit English papers for doctoral students within the same research group to improve his own writing skills. Finally, he sent it to MD1 whom his supervisor had arranged to edit papers for doctoral students but without rewarding this extra work. The textual record summarized in Table 4 shows that Lily and Dong introduced only a few textual changes. MD1 made no changes at all but only gave comments. 
Table 4: Textual changes on DS2's paper by colleague mediators

\begin{tabular}{|l|c|c|c|c|c|c|c|c|}
\hline & \multicolumn{5}{|c|}{ Lily } & \multicolumn{4}{c|}{ Dong } \\
\hline & minor & meso & major & subtotal & minor & meso & major & subtotal \\
\hline Addition & 7 & 3 & & 10 & 1 & & 1 & 2 \\
\hline Deletion & 4 & & & 4 & 1 & & & 1 \\
\hline Rewriting & 5 & & & 5 & 4 & 4 & 1 & 9 \\
\hline Reordering & 6 & & & 6 & & & & \\
\hline Recombining & 2 & 1 & & 3 & & & & \\
\hline Substitution & 4 & & & 4 & 1 & & & 1 \\
\hline Mechanics & 4 & & & 4 & 5 & & & 5 \\
\hline Total & 32 & 4 & & 36 & 12 & 4 & 2 & 18 \\
\hline
\end{tabular}

In fact, Lily returned the edited manuscript to DS2 less than two hours after she received it, far less than the 5-8 hours which Edmunds (2002) suggests is needed by an NES expert working on a paper by an EAL colleague. She made only 36 textual changes, mostly minor in size, clustering in the abstract and the result section, and gave five short in-text comments in Chinese, as in this excerpt in the result section:

Forty (52.6\%) patients were determined to have diagnosed with MAP and 36 (47.4\%) to have with SAP according to the Atlanta criteria. (第一次出现的缩写 是不是要解释. translation: Explain the acronym appearing for the first time)

DS2 sought to explain Lily's reluctance to edit more rigorously:

We are not in the same subfield. She specializes in endocrinology but the paper is about pancreatitis.

However, both Dong and MD1 shared DS2's specialism but made even fewer revisions. Dong effected 18 changes, mainly in the abstract, none crossing sentence boundaries, and gave 10 in-text comments, such as this:

Thymosin $\beta 4$ levels in Patients in MAP group had-was higher median serum thymosin than healthy controls group, 521.6(471.0-560.0) ng/ml vs 332.0 (310.4494.8) ng/ml, $P<0.01$.

这段是对我们假说的解释(translation: This paragraph explains our hypothesis)

MD1 made no textual changes at all but gave seventeen comments, six of which negatively evaluated Dong's comments, and only seven suggested further revision, as here: 
董博此意见似乎不然? (translation: This comment of Dr. Dong seems not that relevant?)

此句写清楚, 随着病程的进展, 血清胸腺素的含量逐渐增加。(translation: Clarify this sentence. As the disease develops, serum thymosin increases gradually.)

Not only did these mediators only make a limited number of small changes or gave a few comments, none consulted the author at all about the work. Close interaction with the author seems to be essential to successful revisions undertaken by professional and committed text mediators working with novice EAL scholars (Luo and Hyland 2017; Flowerdew and Wang 2016). Moreover, the fact that Dong and MD1 preferred to comment, rather than revise the text, and the decision of all three mediators to ignore the introduction and discussion sections, generally considered to be the most rhetorically challenging parts of a scientific paper, suggest that none took the task as seriously as DS2 would have liked. None of the mediators gave DS2 an opportunity to ask questions or clarify his intended meanings. While we have focused here on one paper, this pattern of light editing, and an absence of interaction was repeated across the text data and seems to characterize the low degree of commitment when responding to requests for unpaid favours. There was, in fact, only one exception to this approach where a newly recruited returnee scholar at L2's department edited a paper for L2 carefully.

Obviously, these colleagues were fellow EAL scholars and may have felt they lacked the English academic literacy skills to act as effective text mediators. Neither Lily nor Dong were experts in academic writing themselves and MD1 regularly used an online text mediation service. Even Prof2, a returnee scholar with an impressive publication record, acknowledged:

Even if I edit papers for colleagues, I don't think I can do it well because I'm not trained in language. I don't know how to talk about language and see what is wrong.

It is unclear, however, how far this expressed lack of confidence in academic English underlies the reluctance of colleagues to provide support for their peers. While some respondents mentioned their unfamiliarity with English writing conventions, this may have been to avoid giving offence while declining offering unrewarding and time-consuming favours. The difficulties of recruiting colleagues to edit manuscripts also extended beyond 
China as two international senior scholars, both highly competent academic writers, offered minimal help to our participants. One was a Spanish scholar and editor of a prestigious international English journal who simply gave a few comments without editing the paper Prof4 had sent him. The other was a professor at a US university who edited a paper A7 sent him so superficially that AP7 speculated that it had been done by one of his students.

This reluctance to offer discursive assistance to colleagues has also been noted elsewhere so, for instance, the Iranian healthcare academics in Gholami and Zeinolabedini's (2017) study felt "overtaxed" when asked to edit papers by fellow medical professionals. When they did provide help, moreover, their busy schedule meant they provided very limited textual interventions as we noted above for DS2's paper (Zeinolabedini and Gholami 2016). On the other hand, Lillis and Curry (2010) report how an Anglophone-centre researcher substantially shaped two European academics' manuscript, but we suspect this is not a representative case. In our study, such generosity occurred only rarely and usually among trusted long-term collaborators (e.g. AP5 and his former supervisor) where the mediation favour would eventually be reciprocated.

Soliciting free help from busy colleagues requires idealistic levels of altruism and selflessness in a highly competitive and demanding academic world. Thus AP3, Prof2 and Prof6 routinely turned down requests for textual mediation. When the colleagues did work on manuscripts as non-authorial text mediators, they tend to provide minimal support. Events like L2's experience with his returnee colleague are rare and only likely to take place before the mediator is flooded with text mediation requests. Ever-increasing institutional demands for more teaching, more publications, more administration, more outreach, and so on make unrewarded labour an unrealistic luxury. In China, as elsewhere, it is not uncommon for academics to work 60-80 hours a week and they are rarely looking for additional tasks for little return.

\section{Local coauthors}

A final group of potential collegial agents in the network are coauthors other than supervisors and international collaborators who are rewarded with middle authorship. Such credit is common in scientific publishing and there is no agreement across fields of how authors should be listed in an article by-line nor consensus on what any position in the list implies about the value of their contribution. Names following the lead author may be listed according to their diminishing contributions to the research or, as in mathematics and theoretical computer science, listed alphabetically irrespective of their contribution, while collaborations 
in high-energy physics, notoriously extended, often start with one or two key individuals and then list alphabetically. In many fields, long standing collaborators often rotate themselves on co-authorship lists and some ghost and guest (or honorary) authors perhaps should not be there at all. Certainly, the growth of multiple authorship means that most publishing researchers are now middle-author contributors, with a corresponding uncertainty about the value of these articles to promotion boards (Hyland 2015).

Thus, the value of middle-authorship is uncertain but costs the main authors very little to include colleagues who have edited or rewritten the manuscript. The main authors will still get full citational credit irrespective of the length of author lists. A survey of 142 medical schools in the US and Canada, for instance, shows that the perceived role of authors after the first diminishes quickly, giving middle-authors little credit for publishing in even prestigious journals, with negative consequences for their careers (Wren et al. 2007). In China, most institutions state that middle authorships would not be recognized for hiring decisions, promotion and financial reward.

As a result, only two participants (L1 and DS3) in our study obtained discursive support from middle coauthors. While L1 found the comments of a fellow student helpful, DS3 bemoaned how the colleague who had promised to edit the manuscript had simply corrected some spelling errors. The strategy seems to be regarded with suspicion from both sides. On the one hand, most writers $(21,68 \%)$ dismissed middle coauthors for being no more discursively skillful than themselves, while on the other, coauthors were unwilling to spend time on papers in which they were only given a middle authorship. Prof1, for example, was frustrated by the endless delays of a co-author to check a paper:

They simply aren't motivated by a middle authorship. It means nothing in China.

The fact that our informants seldom obtained writing support by offering middle coauthorship differs from Lillis and Curry's (2010) study in non-Anglophone Europe which found that more writing competent academics may painstakingly shape texts produced by colleagues. In China, colleagues in some groups may also "routinely check each other's manuscript" (Li 2014b: 2). The discrepancy between our findings and the previous ones may be explained by how middle authorship is valued by different research cultures and the views of particular research groups. 


\section{Conclusions and implications}

We need to be cautious in generalizing from a relatively small-scale study such as this, but our data support the broader idea that writing for international publication is a networked activity rather than an individual endeavor. All our authors drew on colleagues as a resource and most also sought assistance from other network agents, notably professional text mediators, overseas contacts and English teachers. The dependence of Chinese authors on international collaborators, for example, is shown by the fact that $25 \%$ of Chinese authored papers in the Web of Science and over half of those in the Nature Index were internationally coauthored (Anderson 2017). We hope to have shown that rather than seeing collegial resources in terms of knowledge differences and power disparities, they can profitably be considered as potential assets and are often integral to the way that a submitted research article emerges from a first draft. Authors assemble relevant resources for papers and arguments emerge into their final shape after passing through the hands of uncredited collaborators, often colleagues, in a network of support. These contributions are more than a general 'context' for knowledge production as they cannot be separated from the text itself: it can constitute the writing (e.g. Canagarajah 2018).

While one's networks of colleagues may be a valuable resource, it is clear from our study that this is not always the case. Writers in many non-Anglophone settings often struggle to meet the demands of their institutions to produce papers in indexed journals. Similar difficulties have been reported for authors in Latin America, Europe, Africa and Southeast Asia (e.g. Corcoran et al. 2019; Martinez and Graf 2016), and for writers in different disciplines (Daly 2016; Hyland 2004). This has encouraged systematic support from universities in many countries in the form of ERPP (English for Research Publication Purposes) courses for PhD students and other novice researchers (e.g. Cargill and Burgess 2008; Li et al. 2018). These courses seek to make the features and structures of published articles explicit to enhance students' writing abilities in English and boost their confidence in international publication. They rarely, however, go beyond rhetorical consciousness-raising to help academics locate themselves "strategically in the relevant social and material networks to generate meaning" (Canagarajah 2018: 15). This study shows that assisting researchers to identify and employ networked resources would be extremely beneficial and that research in this area is urgently needed. At a time when textual analysis of published articles is almost saturated (Swales, 2019), the notion of international publishing as a networked activity opens new frontiers for writing research. 
Such courses, however, are still in their infancy in China and reach only limited numbers of academics. Instead, universities have preferred to focus on the end product and reward success with generous financial incentives and career advancement rather than invest resources to ensure that this success can occur. A recent survey of 48,000 scientific researchers, for example, found that $93 \%$ published purely for promotion in a system geared toward quantity over quality (Zuo 2018). Nor have advances in English language education in China in recent years eliminated an educational system which continues to emphasise grammatical accuracy over rhetorical effectiveness. The general purpose of most tertiary English courses mean that even proficient students often have "low academic writing proficiency" and cannot “write acceptable English compositions" (Cai 2013: 5). Nor are most Chinese academics familiar with the conventions of academic writing in their discipline or the expectations which an international readership might have of argument structure.

In addition to raising researchers' awareness of the possibilities of networked support through ERPP courses, it seems clear from our findings that it may be necessary to provide financial support to encourage collaboration with relevant local professionals who are trained, rewarded and willing to participate in collegial support activities. These might be English teachers, senior scholars, trusted text mediators or local journal editors, but they require an understanding of the local context, familiarity with relevant disciplinary conventions and knowledge of the publishing process. Another possibility to help EAL academics to mobilize network resources is to hire trustworthy professional text mediators, preferably those who are personally known to authors (Matarese 2013); another is to encourage English teachers to take on this role by developing and exploiting their knowledge of research genres. Despite some skepticism (e.g. Lillis and Curry 2010), English teachers have been shown to be of considerable value to academics where one-to-one negotiation of meaning is possible (Luo and Hyland 2016, 2017). There have also been developments, albeit limited to well-funded disciplines, in discipline-specific communications centres to support researchers for language-related problems in international publishing (Breugelmans and Barron 2008).

As greater pressure, more explicit incentives and fiercer competition among academics to publish take a firmer hold on research across the globe, institutions are looking for ways to support the presence of their universities on the world stage. In China, as in many other countries, it is urgent to sustain a demanding research industry to meet the requirements of publishing in SCI journals in English. Mobilizing the considerable resources of colleagues in organized networks of support is a possible solution to this problem. 


\section{NOTES}

1 Text mediators are non-authorial third-parties who provide writing assistance to academic authors (see Luo and Hyland 2016).

\section{REFERENCES}

Anderson, P. (2017). 'More than half of China's research includes international co-authors,' Publishing Perspectives. https://publishingperspectives.com/2017/05/nature-index-chinaresearch-international-co-authors/

Belcher, D. 2007. 'Seeking acceptance in an English-only research world,' Journal of Second Language Writing 16/1: 1-22.

Breugelmans, R. and P. Barron. 2008. 'The role of in-house medical communications centres in medical institutions in nonnative English-speaking countries'. Chest 134/4: 883-885.

Burrough-Boenisch, J. 2003. 'Shapers of published NNS research articles,' Journal of Second Language Writing 12/3: 223-243.

Burrough-Boenisch, J. and V. Matarese. 2013. 'Working with authors to make drafts fit for purpose' in Matarese, V. (ed.): Supporting Research Writing: Roles and Challenges in Multilingual Settings. Chandos Publishing.

Cai, L. J. 2013. 'Students' perceptions of academic writing: A needs analysis of EAP in China', Language Education in Asia, 4/1: 5-22.

Canagarajah, S. 2018. "Materializing "competence": perspectives from international STEM scholars,' The Modern Language Journal 102/2: 1-24.

Cargill, M., and Burgess S. 2008. 'Introduction to the special issue: English for research publication purposes.' Journal of English for Academic Purposes 7/2: 75-76.

Corcoran, J. N., Englander, K., and Muresan, L. M. (eds.). 2019. Pedagogies and Policies for Publishing Research in English: Local Initiatives Supporting International Scholars. Routledge.

Coyne, I. T. 1997. 'Sampling in qualitative research. Purposeful and theoretical sampling; merging or clear boundaries?', Journal of Advanced Nursing 26: 623-30.

Cryanoski, D., Gilbert, N., Ledford, H., Nayar, A., and Yahia, M. 2011. 'The PhD factory', Nature, 472: 276-279.

Daly, N. P. 2016. 'Common words, uncommon uses: The most "discoursally significant" language edits in a corpus of Chinese medical manuscripts', Journal of English for Academic purposes 21: 34-47. 
Duszak, A. and J. Lewkowicz. 2008. 'Publishing academic texts in English: A Polish perspective,' Journal of English for Academic Purposes 7/2: 108-120.

Flowerdew, J. and S. H. Wang. 2016. 'Author's editor revisions to manuscripts published in international journals,' Journal of Second Language Writing 32/2:39-52.

Gholami, J. and M. Zeinolabedini. 2017. 'Peer-to-peer prescriptions in medical sciences: Iranian field specialists' attitudes toward convenience editing,' English for Specific Purposes 45: 86-97.

Hyland, K. 2004. Disciplinary Discourse: Social Interactions in Academic Writing. Ann Arbor, MI: University of Michigan Press.

Hyland, K. 2015. Academic Publishing: Issues and Challenges in the Construction of Knowledge. Oxford, UK: OUP.

Hyland, K. 2016. 'Academic publishing and the myth of linguistic injustice'. Journal of Second Language Writing 32/1:58-69.

ISTIC (Institute of Scientific and Technical Information of China). 2018. Statistical data of Chinese $S$ and T papers. http://www.istic.ac.cn

Jiang, X., E. Borg, and M. Borg. 2017. 'Challenges and coping strategies for international publication: perceptions of young scholars in China,' Studies in Higher Education 42/3: 428-444.

Kaplan, K. 2010. 'Publishing: a helping hand,' Nature 468: 721-723.

Kim, E. Y. 2019. 'Korean scholars' use of for-pay editors and perceptions of ethicality', Publications, 7: 1-12.

Kuld, L., and O'Hagan, J. (2018). Rise of multi-authored papers in economics: Demise of the 'lone star' and why? Scientometrics. 114/ㄹ: 1207-1225.

Kwan, B. S. C. 2010. 'An investigation of instruction in research publishing offered in doctoral programs: the Hong Kong case', Higher Education, 59: 55-68.

Latour, B., and Woolgar, S. 2013. Laboratory life: The Construction of Scientific Facts (3rd edition). Princeton University Press.

Lei, J., and Hu, G. 2015. 'Apprenticeship in scholarly publishing: A student perspective on doctoral supervisors' roles', Publications, 3/1: 27-42.

Li, Y. 2012. 'I have no time to find out where the sentences came from, I just rebuild them: a biochemistry professor eliminating novices textual borrowing,' Journal of Second Language Writing 21/1: 59-70.

Li, Y. 2014a. 'Seeking entry to the North American market: Chinese management academics publishing internationally,' Journal of English for Academic Purposes 13/1: 41-52. 
Li, Y. 2014b. 'Chinese doctors connecting to the English publishing world: Literature access, editorial services, and training in publication skills,' Publications. 2/1: 1-13.

Li, Y. and J. Flowerdew. 2007. 'Shaping Chinese novice scientists' manuscripts for publication,' Journal of Second Language Writing, 16: 100-117.

Li, Y., Flowerdew, J., and Cargill, M. 2018. 'Teaching English for Research Publication Purposes to science students in China: A case study of an experienced teacher in the classroom', Journal of English for Academic Purposes, 35: 116-29.

Lillis, T. M. and M. J. Curry. 2010. Academic Writing in Global Context. Routledge.

Lillis, T. M., and Curry, M. J. 2006. 'Reframing notions of competence in scholarly writing: from individual to networked activity', Revista Canaria de Estudios Ingleses, 53: 63-78.

Liu, C., N. Campbell, E. Gerstner, et al. 2015. Turning Point: Chinese Science in Transition. NPG White paper. http://www.nature.com/press_releases/turning_point.pdf.

Luo, N. 2017. Chinese scientists writing for international publication: The use of mediation services. The University of Hong Kong [unpublished doctoral thesis]

Luo, N. and Hyland, K. 2016. Chinese academics writing for publication: English teachers as text mediators. Journal of Second Language Writing 32/3: 43-55.

Luo, N. and Hyland, K. 2017. 'Intervention and revision: Expertise and interaction in text mediation' Written Communication 34/4: 414-440.

Luo, N. and Hyland, K. 2019. "I won't publish in Chinese now": Publishing, translation and the non-English speaking academic'. Journal of English for Academic Purposes 39/1: 3747.

Martinez, R., and Graf, K. 2016. 'Thesis Supervisors as Literacy Brokers in Brazil', Publications, 4: 1-10.

Mu, C., and Zhang, J. 2018. 'Chinese multilingual scholars' experiences of publishing research in English', Journal of Scholarly Publishing, 25/6: 397-418.

Prest, K. (2017) 'Analysis of Chinese universities' financial incentives for academic publications.' British Council International Education Services. https://educationservices.britishcouncil.org/insights-blog/analysis-of-chinese-universities'-financialincentives-academic-publications

Rozycki, W. and N. Johnston. 2013. 'Non-canonical grammar in best paper award winners in engineering,' English for Specific Purposes 32: 157-169.

Saldaña, J. 2013. The Coding Manual for Qualitative Researchers ( $2^{\text {nd }}$ edition). Sage. 
Simpson, S. 2013. 'Systems of writing response: A Brazilian student's experiences writing for publication in an environmental sciences doctoral program', Research in the Teaching of English, 48/2: 228-49.

Swales, J. M. 2004. Research Genres: Explorations and Applications. Cambridge University Press.

Swales, J. M. 2019. 'The futures of EAP genre studies: A personal viewpoint', Journal of English for Academic Purposes, 38: 75-82.

Wren, J., Kozak, K., Johnson, K., Deakyne, S., Schilling, L., and Dellavalle, R. 2007. 'The write position: A survey of perceived contributions to papers based on byline position and number of authors', EMBO reports, 8: 988-91.

Willey, I. and K. Tanimoto. 2012. "“Convenience editing” in action: comparing English teachers' and medical professionals' revisions of a medical abstract,' English for Specific Purposes 31: 249-260.

Zeinolabedini, M., and Gholami, J. 2016. 'Colleagues helping each other to publish in medical sciences: Iranian field specialists' convenience editing strategies', Learned Publishing, 29/4: 249-58.

Zuo, M. Oct. 30, 2018. 'Most Chinese scientists write academic papers to get promoted, survey finds'. South China Morning Post. 